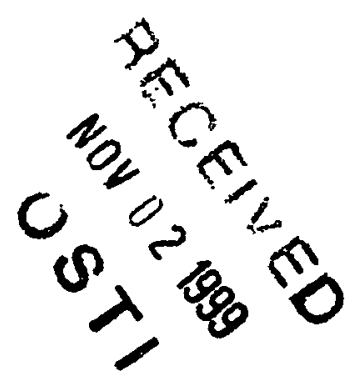

\title{
EFFECTS OF NEUTRON IRRADIATION ON DEFORMATION BEHAVIOR OF NICKEL-BASE FASTENER ALLOYS
}

R. Bajaj, W. J. Mills, B. F. Kammenzind and M. G. Burke

U.S. Department of Energy Contract DE-AC11-98PN38206

\section{NOTICE}

This report was prepared as an account of work sponsored by the United States Government. Neither the United States, nor the United States Department of Energy, nor any of their employees, nor any of their contractors, subcontractors, or their employees, makes any warranty, express or implied, or assumes any legal liability or responsibility for the accuracy, completeness or usefulness of any information, apparatus, product or process disclosed, or represents that its use would not infringe privately owned rights. 


\section{DISCLAIMER}

Portions of this document may be illegible in electronic image products. Images are produced from the best available original document. 
Effects of Neutron Irradiation on Deformation Behavior of Nickel-Base Fastener Alloys -.

R. Bajaj, W. J. Mills, B. F. Kammenzind and M. G. Burke

Bechtel Bettis Inc.

Bettis Atomic Power Laboratory

West Mifflin, Pennsylvania 15122

\begin{abstract}
This paper presents the effects of neutron irradiation on the fracture behavior and deformation microstructure of high-strength nickel-base alloy fastener materials, Alloy X-750 and Alloy 625. Alloy X-750 in the HTH condition, and Alloy 625 in the direct aged condition were irradiated to a fluence of $2.4 \times 10^{20} \mathrm{n} / \mathrm{cm}^{2}$ at $264^{\circ} \mathrm{C}$ in the Advanced Test Reactor. Deformation structures at low strains were examined. It was previously shown that Alloy X-750 undergoes hardening, a significant degradation in ductility and an increase in intergranular fracture. In contrast, Alloy 625 had shown softening with a concomitant increase in ductility and transgranular failure after irradiation. The deformation microstructures of the two alloys were also different. Alloy X-750 deformed by a planar slip mechanism with fine microcracks forming at the intersections of slip bands with grain boundaries. Alloy 625 showed much more homogeneous deformation with fine, closely spaced slip bands and an absence of microcracks. The mechanism(s) of irradiation assisted stress corrosion cracking (IASCC) are discussed.
\end{abstract}

\section{Introduction}

In our previous paper (1), the results of detailed microstructural and microchemical analyses and mechanical properties testing of nonirradiated and irradiated high-strength fastener Alloys X-750 and 625 were reported as part of a major investigation into the possible mechanisms of irradiation-assisted stress corrosion cracking (IASCC). The previous work $(1,2)$ showed that the IASCC susceptibility of HTH Alloy X-750 was correlated with the boron content of the various heats. Low boron $(<10 \mathrm{ppm} \mathrm{B)}$ heats showed little or no IASCC whereas those with high boron showed substantial degradation. Alloy 625 showed little or no susceptibility to IASCC independent of boron content.

The IASCC mechanism study (1) investigated the microstructural and microchemical changes due to irradiation, transmutation effects, and the effect of these changes on the mechanical properties. Two heats of Alloy X-750, one IASCC susceptible and one nonsusceptible to IASCC, were investigated. The two heats showed (a) similar microstructural and microchemical effects (i.e., some grain boundary chromium depletion, irradiation induced voids, black-spot damage and loops within $\gamma^{\prime}$ precipitates), (b) significant increase in yield strength and a decrease in ductility, and (c) an increased degree of intergranularity of fracture. The IASCC susceptible heat showed a significant segregation of B to grain boundaries in the nonirradiated condition and the segregated B transmuted to helium (and lithium) upon irradiation, as evidenced by a presence of bubbles at and in the vicinity of grain boundaries after postirradiation annealing. Grain boundary bubbles were not observed in the non-susceptible heat.

Irradiation of DA-Alloy 625 resulted in black-spot damage, some dissolution of $\gamma$ " precipitates, production of a new phase, radiation softening, increased ductility and, no change in fracture mode.
While the boron transmutation reaction dominated the overall IASCC behavior of Alloy X-750, irradiation effects on the mechanical and deformation properties may also have contributed to the overall cracking response. This paper provides the details of the deformation behavior of three heats of Alloy X-750 (two susceptible and one nonsusceptible) and one heat of Alloy 625. A discussion of all of the mechanisms potentially impacting the IASCC performance of both Alloy X-750 and Alloy 625 is also provided

\section{Experimental Procedures}

For this study, an IASCC-susceptible heat of Alloy X-750 (AI), a non-susceptible heat of Alloy X-750 (A7) and one heat of Alloy 625 (A12) were selected. A limited deformation study of another heat $(\mathrm{A} 10)$ was also conducted. The chemical composition of the materials is provided in Table 1. The mean grain diameter of Alloy $\mathrm{X}-750$ was $100-120 \mu \mathrm{m}$ and that of Alloy 625 was $10-20 \mu \mathrm{m}$. Specimens were irradiated to a total fluence of $2.4 \times 10^{20} \mathrm{n} / \mathrm{cm}^{2}$ (E $>1 \mathrm{MeV}$ ) at $264^{\circ} \mathrm{C}$ (including $\gamma$ heating) and postirradiation tested at $288^{\circ} \mathrm{C}$.

Tensile specimens with a uniform gage section of $1.25 \mathrm{~mm} \times 2.5 \mathrm{~mm}$ $x 19 \mathrm{~mm}$ were deformed to strain levels of either 0 or $2 \%$ prior to irradiation. The $2 \%$ strain prior to irradiation represents strain ahead of a thread root or crack in a fastener prior to service. Both types of specimens were deformed to a post-irradiation plastic strain of $2 \%$. This strain level was sufficiently beyond the yield point to establish bulk deformation behavior, yet low enough to permit delineation of dislocation structures via transmission electron microscopy (TEM).

High levels of deformation result in high dislocation densities that are difficult to interpret. Results presented herein show that these levels of deformation achieved the intended goal. In addition, two other specimens of Alloy X-750 (heat A10) in the nonirradiated and irradiated condition, were tested to fracture and examined. Specimens were also tested to fracture to determine their tensile properties (for results of tensile properties see (1)). SEM examined fracture surfaces of these specimens. Deformation microstructures of the specimens were evaluated by TEM. These examinations were conducted on thin-foil specimens derived from the gage section of the tensile specimens. The discs were first thinned to $\sim 125 \mu \mathrm{m}$ by grinding, then electropolished to electron transparency in a solution of $20 \% \mathrm{HClO}_{4}-\mathrm{CH}_{3} \mathrm{OH}$ at $-40^{\circ} \mathrm{C}$. The electron-transparent foils were examined either in a Philips CM-12 or a Philips CM-30 TEM operating at $120 \mathrm{keV}$ or $300 \mathrm{keV}$, respectively.

To evaluate the dislocation structures in the nonirradiated, deformed specimens, conventional 2-beam conditions were employed. To determine the Burgers vector for the dislocations in the deformed specimens, conventional g.b analyses were performed. Because these alloys deform via planar slip, it was necessary to take this inhomogeneity into account when determining an average dislocation density. It was concluded that 
the most appropriate way to obtain dislocation density data was to determine the average dislocation content within a slip band, and then determine the average slip band spacing for each deformation condition. Thus, in this study, a variation of the line intercept method was used to determine dislocation densities. This method involved a two-stage process. The first stage entailed the estimation of the dislocation line length per unit area of slip band. (This was accomplished by measuring the number of dislocation intersections with a test ellipse per unit area of slip band in the test plane). The average slip band spacing was determined by counting the number of slip bands intersecting a test line in the TEM images.

\section{Results}

\section{Fractography}

In the nonirradiated condition Alloy $X-750$ showed mixed transgranular/intergranular fracture where the intergranular regions were separated by a network of small dimples associated with void sheet formation (3), (4). Irradiation resulted in an increase in the degree of intergranularity of the fracture with heat A10 exhibiting the greatest amount. The transgranular regions of the irradiated specimens exhibited a somewhat faceted appearance. Typical fracture surfaces are presented in Figure 1.

Alloy 625 failed by a transgranular ductile dimple rupture process with no evidence of intergranular fracture in both the nonirradiated and the irradiated conditions. Little or no difference was observed between the fracture surfaces of nonirradiated and irradiated specimens. In both cases the dimples nucleated at intragranular inclusions with larger inclusions nucleating larger dimples. Figure 2 contains typical micrographs of the nonirradiated and irradiated specimens.

\section{Deformation microstructures}

Nonirradiated Alloy X-750

\section{$2 \%$ Strain}

A general representation of the extent of deformation was obtained from the TEM examination of several grains. All samples were characterized by slip on $\{111\}$ planes in $<110\rangle$ directions as expected for face centered cubic (fcc) materials. The dislocation motion occurred in well-defined slip bands (planar slip). There was considerable grain-to-grain variation in slip band density, consistent with the expected effect of grain orientation. The density of dislocations in the $A 1$ and $A 7$ samples strained to $2 \%$ was estimated to be approximately $2 \times 10^{10} \mathrm{~cm} / \mathrm{cm}^{3}$ for both materials. Dislocation densities near-grain boundary regions of the A7 specimen were slightly higher $\left(\sim 6 \times 10^{10} \mathrm{~cm} / \mathrm{cm}^{3}\right)$ suggesting enhanced dislocation activity at the grain boundary regions which is required to maintain continuity between adjacent grains.

Dislocation pairs were occasionally observed within the slip bands. This type of behavior has been reported by many investigators (e.g., (5)), and it is related to the generation of antiphase domain boundaries (APBs) within the $\mathrm{LI}_{2}$-ordered $\gamma^{\prime}$ precipitates. The spacing of the paired dislocations varied from pair to pair; spacings from $\sim 20 \mathrm{~nm}$ to $\sim 100 \mathrm{~nm}$ were observed. Undulations along the dislocation length (Figure 3 ) were related to the bowing of the dislocation between the $\gamma^{\prime}$ precipitates. Similar deformation structures were observed in both heats. Figure 3 also provides evidence of slip band intersections, in which one slip band has locked or pinned another band. Also, the grain boundary regions in both heats exhibited increased dislocation activity (termed as "dislocation debris").
A preliminary analysis indicated that the dislocation pairs were perfect undissociated dislocations with Burger's vector of $a / 2$ $<110\rangle$. However, it has been shown by Carter et al. (6) that there is dissociation of perfect dislocations even in higher stacking fault energy materials such as pure $\mathrm{Ni}\left(-120-130 \mathrm{~mJ} / \mathrm{m}^{2}\right)$ and pure $\mathrm{Cu}$ $\left(-40 \mathrm{~mJ} / \mathrm{m}^{2}\right)$. Thus, it is likely that there is limited dissociation of these $a / 2<110>$-type dislocations in Alloy X-750. Detailed examination of the weak beam dark-field images of heat A7 strained to $2 \%$ (Figure 3 ) showed evidence of dissociation in the form of narrow stacking fault contrast.

\section{$4 \%$ Strain}

Specimens deformed to $4 \%$ strain contained numerous slip bands with high dislocation densities. However, the measured dislocation densities of the $2 \%$ strain and $4 \%$ strain specimens were similar (within the uncertainty of the technique). In the near-grain boundary regions an enhanced dislocation density of $\sim 6 \times 10^{10} \mathrm{~cm} / \mathrm{cm}^{3}$ was measured for heat A7.

The observation of dislocations pairs was not prevalent at this strain level. This may be related to the enhanced dislocation activity within the slip bands at higher strain. The dark-field images of heats A1 and A7 provided indications of limited dissociation (with stacking fault-type contrast), and evidence of fringe contrast associated with the shearing of the $\gamma^{\prime}$ precipitates within the slip band. Dislocation loops were associated with some larger $\gamma^{\prime}$ precipitates in the specimens strained to $4 \%$.

\section{Irradiated Alloy X-750}

\section{$2 \%$ Strain}

The deformation structure of specimens of $\mathrm{Al}$ and $\mathrm{A} 7$ was characterized by the presence of slip bands, similar to those observed in the nonirradiated specimens. The low magnification TEM montage of Figure 4 provides an overall image of the slip band distribution in these specimens. The dislocation density was difficult to estimate because the existence of the irradiationinduced loops and fine cavities (described in (1)) precluded imaging discrete dislocations in the slip bands. However, the estimated dislocation densities were $\sim 2 \times 10^{10} \mathrm{~cm} / \mathrm{cm}^{3}$ for the Al specimen, and $\sim 4 \times 10^{10} \mathrm{~cm} / \mathrm{cm}^{3}$ for the $A 7$ specimen. Examples of the $\{111\}$ slip planes are presented in Figure 4. It was noted that the slip band density appeared to be reduced in the irradiated specimens, but this may be due to the inability to adequately image the deformation structure because of the complicating contrast effects from the loops and cavities.

Examination of the grain boundary regions revealed the presence of fine cracks associated with slip bands impinging at intergranular carbides. Figure 5 shows a well-defined band of deformation extending across a grain and impinging at both bounding grain boundaries. At each boundary intersection, a well-defined microcrack is visible. These microcracks were noted in both $\mathrm{Al}$ and $A 7$ specimens. The A10 specimen deformed to failure $(2.4 \%$ strain) also showed numerous intergranular cracks, as well as racks associated with fractured intragranular MC-type inclusions.

\section{$4 \%$ Strain ( $2 \%$ prestrain $+2 \%$ postirradiation strain)}

Deformation structures in these samples were similar to those observed in the specimens strained $2 \%$. Deformation structures were characterized by planar slip, and the proportion of slip bands qualitatively appeared to increase with increasing strain. However, the dislocation density measured for each material was approximately $1 \times 10^{10} \mathrm{~cm} / \mathrm{cm}^{3}$ for the $\mathrm{Al}$ specimen and $\sim 2 \times 10^{10}$ $\mathrm{cm} / \mathrm{cm}^{3}$ for the A7 sample. The somewhat lower densities of dislocations measured in the specimens strained $4 \%$ compared with 
those strained $2 \%$ are not considered to be significant because of the difficulty in imaging and counting dislocations in the slip bands. Again, imaging discrete dislocations within the slip bands was precluded by the complicating contrast effects associated with the irradiation-induced damage. Like the $2 \%$-strained specimens, these samples were also characterized by the presence of fine microcracks or voids associated with the intersection of slip bands with intergranular carbides.

The observation of microcracks that developed at the intersection of slip bands with intergranular carbides in Alloy X-750 prompted further analysis to determine whether this type of feature was unique to the behavior of irradiated Alloy X-750, or rather a common aspect of fracture in nonirradiated materials as well. To address this concern, a nonirradiated specimen of Alloy X-750 heat A10 was deformed to failure (approximately $20 \%$ failure strain) and subsequently examined using TEM. Characterization of specimens obtained from the near-fracture surface region of the failed A10 sample revealed the presence of cracks at the intersection of slip bands with intergranular carbides, similar to that observed in the neutron-irradiated Alloy X-750 specimens strained to $2 \%$ and $4 \%$. In particular, similar intergranular cracks associated with slip band intersection at carbides were observed in the irradiated A10 sample that was deformed to failure $(2.4 \%)$. Thus, it appears that the effect of neutron irradiation is to greatly enhance the formation of these incipient cracks at applied strains that would not induce cracking in the nonirradiated condition. This dramatic reduction in the resistance to intergranular crack formation is related to the increased hardening caused by neutron irradiation. This also points to the mechanism of failure in Alloy X-750, i.e., the linking of cracks at the grain boundaries. Figure 6 contains an example of these incipient cracks in the nonirradiated and irradiated $\mathrm{A} 10$ specimen deformed to failure.

\section{Nonirradiated and Irradiated DA-Alloy 625 (Heat A12)}

Nonirradiated DA-Alloy 625 was characterized by a deformation substructure consisting of finely spaced slip bands along $\{111\}$ planes, Figure 7. The density of slip bands appeared to be higher in the specimen strained to $4 \%$ than in the specimen strained to $2 \%$. In addition, many dislocations were present that were not associated with the slip bands; these dislocations were related to the thermomechanical processing where the material was direct aged after hot-working.

The dislocation substructure in the irradiated material was essentially the same as in the nonirradiated condition. The irradiated material continued to exhibit a fine slip band structure with a slip band density that appeared to increase with increasing strain. In the nonirradiated material dislocation densities were measured to be in the range of $1 \times 10^{11}$ and $2 \times 10^{11} \mathrm{~cm} / \mathrm{cm}^{3}$ following $2 \%$ and $4 \%$ strain, respectively. In the irradiated condition, somewhat smaller dislocation densities were measured following the same strains $\left(4 \times 10^{10}\right.$ and $\left.7 \times 10^{10} \mathrm{~cm} / \mathrm{cm}^{3}\right)$. These differences are considered within the experimental errors of measurement.

Dislocation pairs and closely spaced quartets (a group of 4 dislocations) were occasionally observed in the deformed nonirradiated material, Figure 8 . These features appeared to be composed of nondissociated perfect dislocations. These observations are consistent with the observed deformation structure in a commercial $\gamma^{\prime \prime}$ (and $\gamma^{\prime}$ ) hardened Alloy 718 (5). Dislocation pairs and quartets may be a result of moving dislocations interacting with different variants of $\gamma$ " precipitates. Dislocation pairs can form when dislocations interact with one variant of $\gamma^{\prime \prime}$ (c-axis parallel to
[001] direction), whereas quartets can form when a dislocation interacts with the other two $\gamma^{\prime \prime}$ variants $(5,7)$. The movement of dislocations in pairs and quartets restores the order in the $\gamma^{\prime \prime}$ after the group has moved through. Individual dislocations in the irradiated material were difficult to resolve due to the contrast effects associated with precipitates and radiation damage, but some dislocation pairs and quartets were occasionally observed. Also, a very limited amount of what appear to be deformation twins were observed in irradiated strained samples.

\section{Discussion}

\section{Effect of Neutron Irradiation on the Deformation Behavior of Alloy $X-750$ and DA-Alloy 625}

Radiation hardening and loss of ductility in Alloy X-750 has been reported and discussed before (1) and therefore will not be further discussed here. However, the deformation structure and failure mechanism of Alloy X-750 before and after irradiation has not been studied previously. It is shown here that Alloy X-750 deforms by planar slip where deformation occurs in parallel, well-defined slip bands containing a high dislocation density. A wide variation in slip band density occurs from grain to grain. Because of the relatively low stacking fault energy of this alloy, dislocation cell formation, which requires dislocation cross slip, does not occur. At grain boundaries, a high concentration of dislocations occurs with dislocations being distributed heterogeneously. This "dislocation debris" further damages grain boundaries and results in the formation of cavities that grow into microcracks. The stress concentration is most severe at the intersections of slip bands with grain boundaries, especially in the vicinity of carbide precipitates. With increasing strain these microcracks link together and cause failure at the grain boundaries. This appears to be the mechanism of failure of nonirradiated Alloy X750 as determined from the microscopy of heat A10. Similar qualitative features of deformation were evident in the irradiated materials (A1, A7 and A10) except that the microcracks were observed at strains as low as $2 \%$ (failure occurred in $A 7$ at a strain of $2.4 \%$ ). This indicates that irradiation increases the propensity of microcrack formation and perhaps the linking of microcracks. The most important contributor to the higher crack propensity is the increased matrix hardening due to irradiation produced damage (black spot damage, dislocation loops and voids) as measured by nearly a $40 \%$ increase in yield stress (1). The occurrence of intergranular microcracking in heat A7 is particularly significant since it contains only $2 \mathrm{ppm}$ boron, so helium embrittlement of grain boundaries is not a factor. Therefore, irradiation strengthening alone must be the cause of microcracking in this heat. In IASCC-susceptible heats, which contain $>10 \mathrm{ppm}$ boron, the synergistic effect of matrix hardening and reduced grain boundary cohesive strength by a helium embrittlement mechanism appears to be responsible for grain boundary cracking.

Irradiated Alloy X-750 also exhibited a reduced tendency for strain hardening as evidenced by a smaller difference between the yield stress and the ultimate tensile stress (1). This implies that, in the irradiated material, very little additional stress is required to produce large strains. This is believed to be due to localization of deformation in slip bands. Once the slip bands are formed further, deformation occurs in these bands (as opposed to nucleating new bands) causing additional stress concentration, which nucleates microcracks. Once microcracks are formed, the increased stress causes growth of the microcracks in preference to the formation of additional slip bands. This may, in part, be responsible for the observation of a lack of a significant increase in dislocation density in the irradiated materials 
from $2 \%$ strain to $4 \%$ strain. SEM observations also support the above conclusion since the intergranular facets showed dimples initiating at the carbide precipitates in both nonirradiated and irradiated condition. However, the dimples were shallower in the latter indicating they initiated and linked at lower strains.

DA-Alloy 625 had exhibited irradiation softening and an increase in ductility by the author's (1). Claudson (8) also reported irradiation-induced softening in A625. Claudson irradiated A625 $\left(1038^{\circ} \mathrm{C} / \mathrm{lh} / \mathrm{WQ}+704^{\circ} \mathrm{C} / 25 \mathrm{~h} / \mathrm{WQ}\right)$ at $280^{\circ} \mathrm{C}$, to fluences up to $1.5 \times 10^{21} \mathrm{n} / \mathrm{cm}^{2}$ (E>1Mev). At a test temperature of $649^{\circ} \mathrm{C}$, a $14 \%$ decrease was observed in YS after irradiation to a fluence of $1.03 \times 10^{20} \mathrm{n} / \mathrm{cm}^{2}$. Further irradiation resulted in a modest increase in YS with a $6 \%$ increase after $1.5 \times 10^{21} \mathrm{n} / \mathrm{cm}^{2}$.

Irradiation softening in A625 may be the result of a reduction in the strengthening potential of $\gamma$ " due to partial dissolution and radiation induced point defect damage of $\gamma$ ". The reduction in the strengthening ability of the $\gamma$ " apparently offsets matrix strengthening due to radiation damage. Partial dissolution of $\gamma$ " and irradiationinduced point defects within the $\gamma^{\prime \prime}$ and surrounding matrix were observed after irradiation at $360^{\circ} \mathrm{C}$ along with precipitation of a new $\mathrm{Pt}_{2} \mathrm{Mo}$-type phase $(1,9)$. After irradiation at $264^{\circ} \mathrm{C}$, damage in $\gamma^{\prime \prime}$ was observed (9) with a slight reduction in average $\gamma^{\prime \prime}$ size. The emergence of the new phase was only indicated by a presence of diffuse rings in the [001] electron diffraction patterns.

The deformation behavior of DA-A625 was essentially unaffected by irradiation. The dissolution of $\gamma^{\prime}$ and the precipitation of the new phase did not affect the deformation microstructure perceptibly and the fractography also did not show significant differences. Thus, the mechanism of deformation in failure was unchanged.

\section{Comparison of Alloy X-750 and Alloy 625}

The deformation structures observed in nonirradiated and irradiated Alloy X-750 specimens were similar to those in DA-Alloy 625 (heat A12) in that the deformation occurred via planar slip, with the production of numerous slip bands. However, an important difference between these alloys is the extent of slip band formation. DA-Alloy 625 (A12) was characterized by a high density of very finely spaced slip bands, as compared with the lower density of slip bands in Alloy X-750 in both the nonirradiated and irradiated conditions. This may be related to: 1 ) the finer grain size of the material; 2) the different shape, structure, composition, antiphase boundary energy, and coherency strain of the strengthening precipitates $\left(\mathrm{DO}_{22}\right.$-ordered $\gamma^{\prime \prime}$ in Alloy 625 versus $\mathrm{Ll}_{2}$-ordered $\gamma^{\prime}$ in Alloy X-750); 3) differences in stacking fault energy; and 4) matrix strength. The increased homogeneity of deformation (i.e., a high density of slip bands) reduces the stress concentration by evenly distributing the strain. This, in turn, reduces the tendency for cracking (i.e., fine cracks associated with the intergranular carbides and intersecting slip bands) in DA-Alloy 625 for the same levels of deformation that generated cracks in Alloy X-750. Furthermore, DA-Alloy 625 undergoes radiation softening (lowering of the yield stress during irradiation) as opposed to significant radiation hardening observed for Alloy X-750. Radiation softening results in a reduced stress concentration at the grain boundaries, thus increasing post-irradiation ductility.

\section{IASCC Mechanisms}

All three heats of Alloy X-750 (A1, A7, and A10) showed similar qualitative deformation behavior. It was not possible to quantitatively discriminate between heats $\mathrm{Al}$ and $\mathrm{A} 7$ i.e., the slip band and dislocation densities were comparable. This leads to a conclusion that the deformation behavior is not a discriminating factor in IASCC. Additionally, it was previously shown that irradiation-induced segregation, microstructural and micro-chemical changes, and the mechanical behavior or the IASCC-susceptible heat $\mathrm{Al}$ and the nonsusceptible heat A7 were also similar. The only difference observed between the two heats was the presence of a high concentration of boron at the grain boundaries in the nonirradiated condition, and a high concentration of helium at and in the vicinity of grain boundaries after irradiation. The presence of helium was inferred by a high concentration of bubbles near grain boundaries in the post-irradiation annealed ( $\mathrm{lh}$ at $800^{\circ} \mathrm{C}$ ) IASCC-susceptible heat $\mathrm{Al}$. This heat treatment was designed to agglomerate transmutation-produced helium into resolvable "bubbles". Helium in the grain boundaries is known to reduce their cohesive energy. Of all the possible mechanisms considered, it is concluded that the IASCC susceptibility of heat Al is mainly due to transmutation products generated by neutron irradiation. An absence of IASCC in Alloy 625 is consistent with the absence of transmutation products at the grain boundaries, although other factors such as irradiation softening and uniformity of deformation may further enhance its resistance to IASCC.

The conclusion drawn above that the IASCC degradation in Alloy $\mathrm{X}-750$ is primarily due to the transmutation effects does not, however, preclude synergistic effects between this mechanism and the others. For example, the presence of the transmutation products in the grain boundaries may enhance the propensity for grain boundary cracking. Similarly, irradiation-induced strengthening may also increase the planarity of slip, and thereby further increase the grain boundary crack propensity by shifting the deformation from the grain interior to the grain boundaries. Table 2 summarizes the observations related to each of the mechanisms investigated, and supports the conclusion previously drawn (Reference 1). The conclusion drawn from the present work is that while other mechanism may be contributing, the primary mechanism of IASCC degradation in Alloy X-750 is the weakening of grain boundaries due to a presence of transmutation products. By the same token, the resistance of DA-Alloy 625 to IASCC is due to the absence of radiation-induced strengthening, segregation, slip planarity and grain boundary transmutation products.

\section{Conclusions}

An investigation of the effects of irradiation on deformation behavior of HTH Alloys X-750 was conducted to augment the previous investigation into the mechanisms of IASCC in Alloy X750 and a lack thereof in Alloy 625. Alloy X-750 deforms by a planar slip mechanism in a heterogeneous manner with a notable increase in dislocations in the grain boundary regions. The irradiated material also deforms heterogeneously in a planar mode, but unlike the nonirradiated material, microcracks start to form at the intersections of slip bands with grain boundaries at low strains. The deformation behavior of the two heats (one IASCC susceptible and one nonsusceptible) was similar. These results combined with the results of our previous study (Ref.1) show that irradiation effects the microstructure, microchemistry, mechanical properties and deformation behavior of Alloy X-750; however, these changes were not discriminating factors in IASCC behavior because both the susceptible and nonsusceptible heat showed similar effects. The only discriminating feature was boron concentration on grain boundaries. These findings lead to the 
conclusion that the primary mechanism of IASCC in Alloy X-750 is the transmutation of boron at the grain boundaries.

Nonirradiated and irradiated Alloy 625 exhibited homogeneous deformation associated with fine, closely spaced planar slip bands. Irradiation partially dissolved the $\gamma$ " phase and resulted in lower strength and increased ductility. The homogeneous deformation mode, radiation softening and a lack of transmutation effects in Alloy 625 are consistent with its IASCC-resistant response.

\section{Acknowledgments}

The authors thank J. Haugh and L. Edelson formerly of Westinghouse Electric Corp. for performing some of the TEM analysis. This work was sponsored by the DOE under Contract DE-AC11-98PN38206 with Bechtel Bettis, Inc.

\section{References}

1. R.Bajaj et al., in Seventh International Symposium on Environmental Degradation of Materials in Nuclear Power Systems-Water Reactors, Eds. G.P. Airey et al. (NACE, 1995) 1093.

2. W.J. Mills, et al., in Sixth International Symposium on Environmental Degradation of Materials in Nuclear Power Systems- Water Reactors, (TMS, 1993), 633.

3. T.B.Cox and J.R.Low, Jr., Met. Trans. 5 (1974) 1457.

4. H.C.Rogers in Ductility (ASM, 1966) 31 .

5. J.M. Oblak et al. Met. Trans, 5 (1974) 143.

6. C.B. Carter and P. B. Hirsch, Phil. Mag.,35 (1977) 1509.

7. M. Sundararaman et al., in Superalloys $718,625,706$ and

Various Derivatives, ed. E.A. Loria (TMS, 1994) 419.

8. T.T. Claudson, in Effects of Radiation on Structural Materials -ASTM STP 426 (ASTM, 1967) 67.

9. M.G. Burke and R. Bajaj, Microscopy \& Microanalysis 96, Eds. G.W. Bailey et al. (San Francisco Press, 1996) 994

10. M. Sundararaman et al. Met. Trans, 30 (1999) 41.

Table 1. Chemical Composition of Fastener Alloys (wt.\%)

\begin{tabular}{|c|c|c|c|c|c|c|c|c|c|c|c|c|c|c|}
\hline Alloy & Heat & C & Mo & $\mathrm{Cr}$ & $\mathrm{Ni}$ & Co & $\mathrm{Fe}$ & $\mathrm{Cu}$ & $\overline{\mathbf{P}}$ & $\mathrm{Nb}$ & $\mathrm{Ta}$ & $\mathrm{Ti}$ & $\overline{\mathrm{Al}}$ & $\mathrm{B}, \mathrm{ppm}$ \\
\hline \multirow{3}{*}{$X-750$} & Al & 0.041 & 0.02 & 15.3 & 71.8 & 0.02 & 8.05 & 0.04 & 0.002 & 0.96 & 0.01 & 2.6 & 0.75 & 28 \\
\hline & A7 & 0.035 & 0.01 & 15.9 & 72.5 & 0.01 & 8.06 & 0.01 & 0.002 & 0.992 & - & 2.6 & 0.68 & 2 \\
\hline & A 10 & 0.072 & 8.51 & 15.5 & 71.2 & 0.07 & 8.33 & 0.01 & 0.007 & $1.0^{\prime}$ & - & 0.27 & 0.8 & 70 \\
\hline A625 & A12 & 0.033 & 9.04 & 21.8 & 60.9 & 0.1 & 3.6 & 0.27 & 0.006 & $3.6^{1}$ & 0.02 & 0.3 & 0.31 & 20 \\
\hline
\end{tabular}

$'=\mathrm{Nb}+\mathrm{Ta} \mathrm{S}_{\mathrm{s}} 0.002, \mathrm{P}_{\mathrm{s}} 0.007, \mathrm{Zr}_{\mathrm{s}} 0.05, \mathrm{Mn}_{\mathrm{s}} 0.1, \mathrm{~V}_{\mathrm{s}} 0.02, \mathrm{Si}_{\mathrm{s}} 0.11$ 
Table 2. Summary of IASCC Mechanistic Observations

\begin{tabular}{|c|c|c|c|c|c|c|c|}
\hline Alloy & Heat & IASCC & $\begin{array}{l}\text { Radiation-Induced } \\
\text { Segregation } \\
\text { (Ref. I) }\end{array}$ & $\begin{array}{c}\text { Radiation-Induced } \\
\text { Microstructural Changes } \\
\text { (Ref. 1) }\end{array}$ & $\begin{array}{l}\text { Mechanical Behavior } \\
\text { (Ref. 1) }\end{array}$ & $\begin{array}{l}\text { Deformation } \\
\text { Behavior }\end{array}$ & $\begin{array}{c}\text { Boron } \\
\text { Transmutation } \\
\text { Effects } \\
\text { (Ref. 1) }\end{array}$ \\
\hline \multirow[t]{2}{*}{$X-750$} & Al & Yes & $\begin{array}{l}\text { AEM: Slight gb Cr } \\
\text { depletion } \\
\text { FEG-STEM: } \\
\text { - Slight gb Cr } \\
\text { depletion; No segre- } \\
\text { gation of Si or P; }\end{array}$ & \multirow[t]{2}{*}{$\begin{array}{l}\text { Similar effects in both } \\
\text { heats: } \\
\text { "Black spot" damage } \\
\text { - Small voids } \\
\text { - Dislocation loops } w / \gamma \text { ' }\end{array}$} & \multirow[t]{2}{*}{$\begin{array}{l}\text { Similar effects in both } \\
\text { heats: } \\
\text { - } \uparrow \text { in } \sigma_{\text {Yieds }} \\
\text { - } \downarrow \text { in ductility } \\
\text { mixed transgranular/ } \\
\text { intergranular fracture }\end{array}$} & \multirow[t]{2}{*}{$\begin{array}{l}\text { Similar effects } \\
\text { in both heats: } \\
\text { - Planar slip } \\
\text { - Incipient } \\
\text { cracking at } \\
\text { gb/slip band } \\
\text { intersections }\end{array}$} & $\begin{array}{l}\quad \text { Yes* } \\
\text { Evidence of B } \\
\text { transmutation } \\
\text { products in the } \\
\text { vicinity of gbs }\end{array}$ \\
\hline & A7 & No & $\begin{array}{l}\text { AEM: Slight gb Cr } \\
\text { depletion }\end{array}$ & & & & No \\
\hline 625 & A 12 & No & $\begin{array}{l}\text { AEM: No depletion or } \\
\text { segregation }\end{array}$ & $\begin{array}{l}\text { "Black spot" damage } \\
\text { - Dislocation loops } \\
\text { - Precipitation of a new } \\
\mathrm{Pt}_{2} \text { Mo-type phase }\end{array}$ & $\begin{array}{l}\text { - } \downarrow \text { in } \sigma_{\text {Yield }} \\
\text { - } \uparrow \text { in ductility } \\
\text { Transgranular fracture- } \\
\text { microvoid coalescence }\end{array}$ & $\begin{array}{l}\text { - Fine-scale } \\
\text { planar slip } \\
\text { - No gb } \\
\text { cracking }\end{array}$ & No \\
\hline
\end{tabular}

"Iradiated samples were annealed at $800^{\circ} \mathrm{C}$ for $1 \mathrm{~h}$ to eliminate the radiation damage and agglomerate He into "bubbles". 

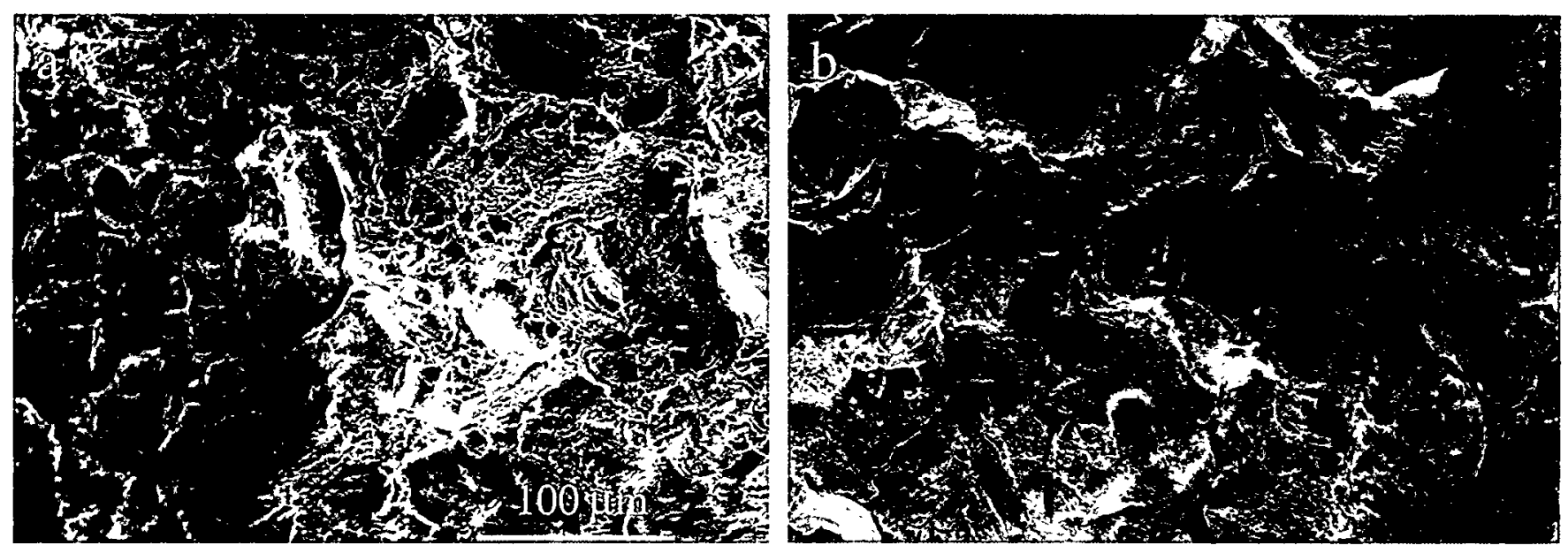

Figure 1. Secondary electron images of (a) nonirradiated and (b) irradiated Alloy X-750 deformed to failure.
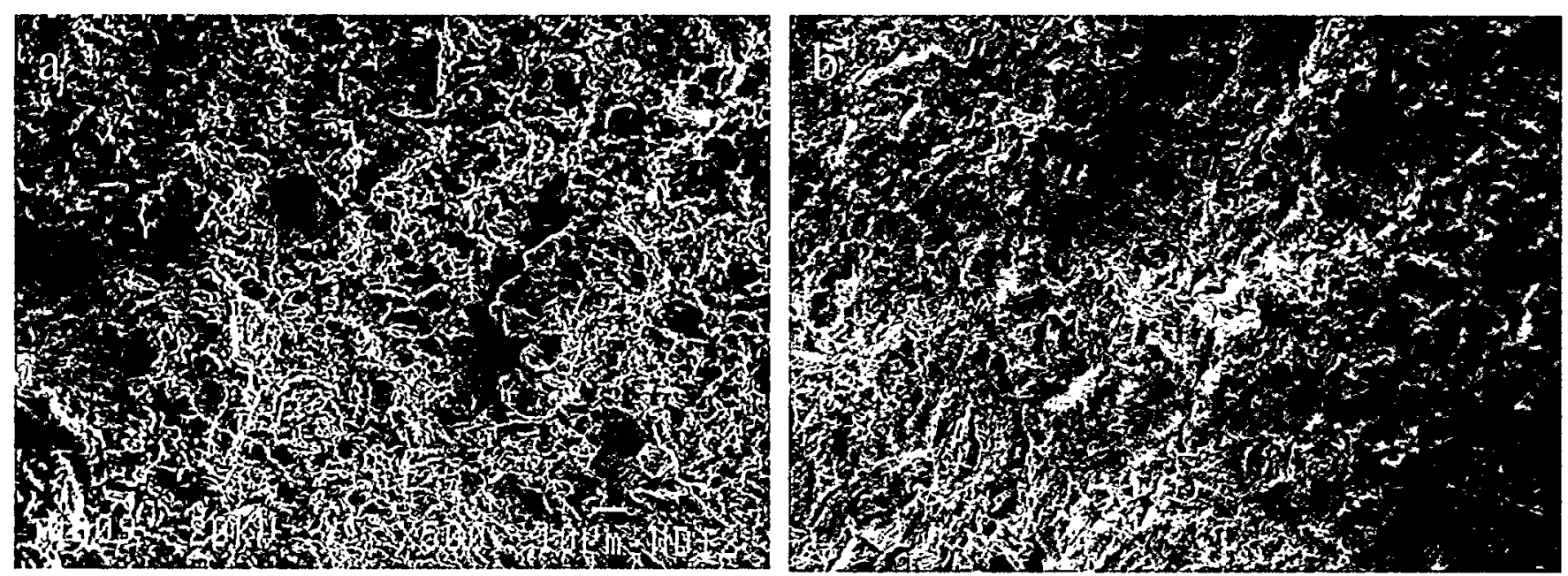

Figure 2. Secondary electron images of (a) nonirradiated and (b) irradiated DA-Alloy 625 deformed to failure.
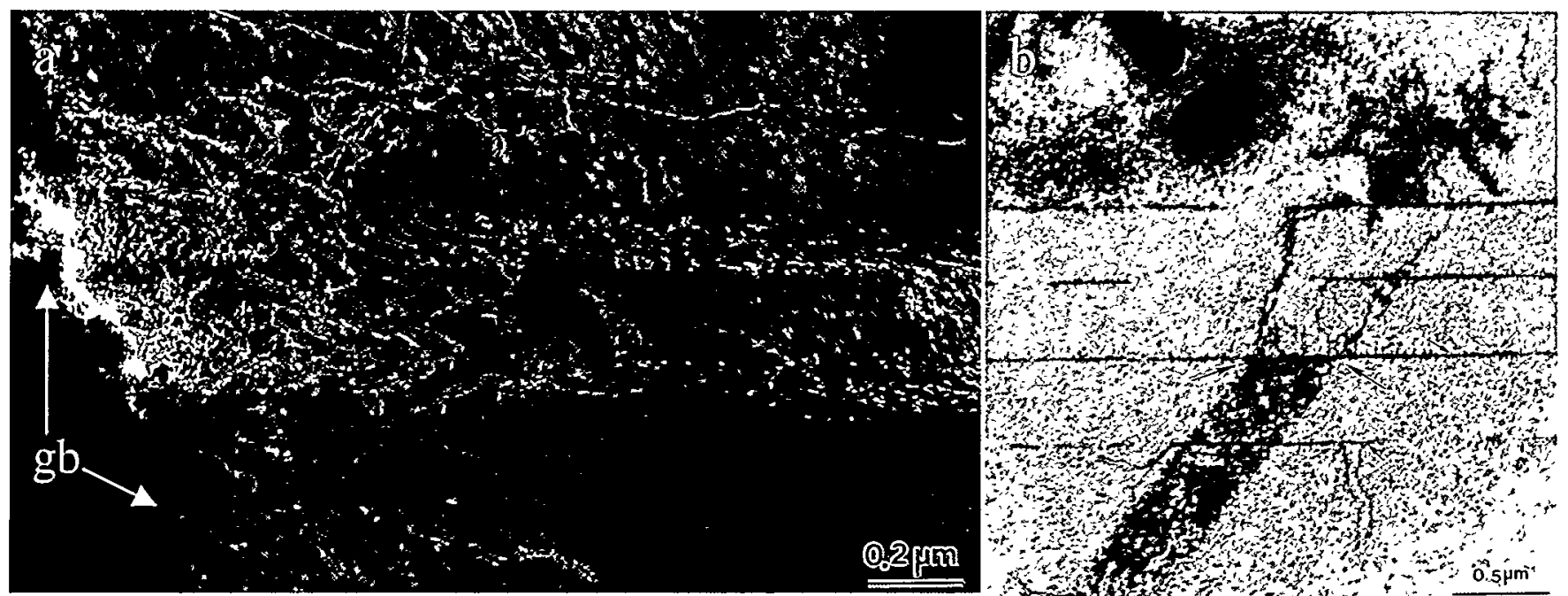

Figure 3. (a) Dark-field TEM image showing dislocations in slip bands in Alloy X-750 deformed 2\%. Note the increased dislocation activity near the grain boundary (gb). (b) Bright-field TEM image showing intersecting slip bands (arrowed). 


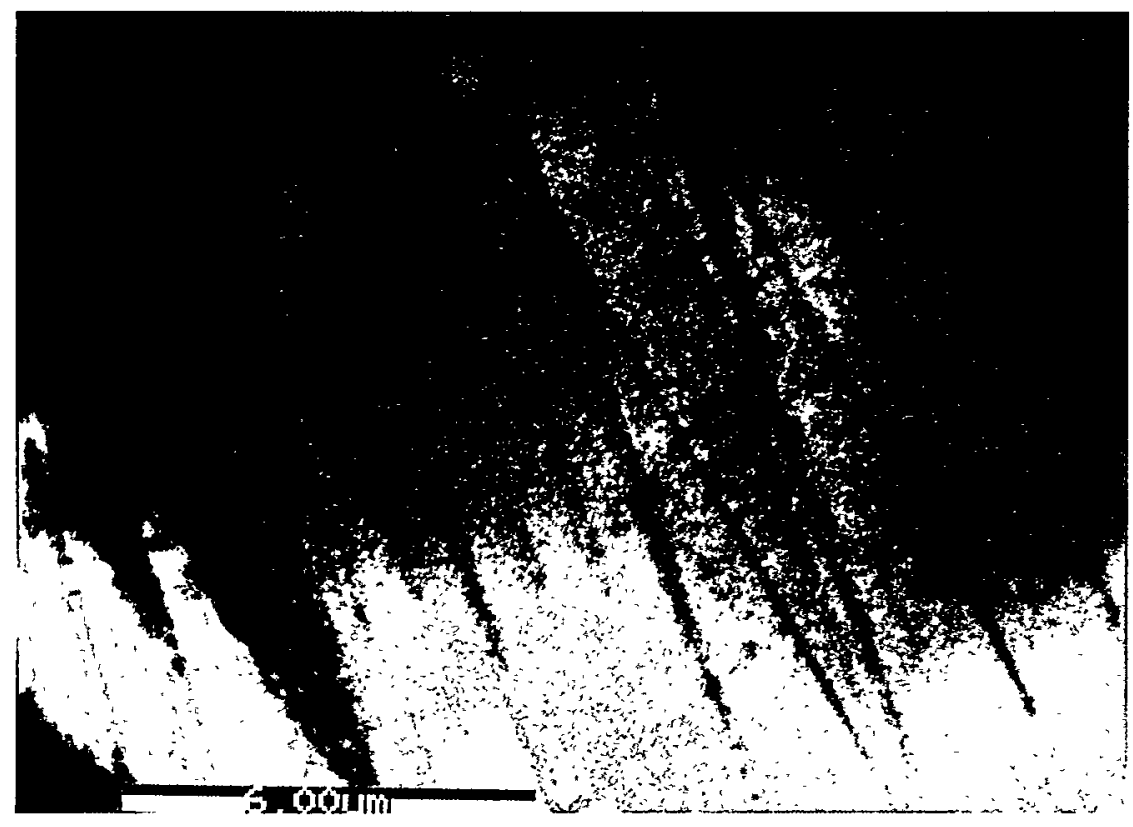

Figure 4. Scanning Transmission Electron Micrograph showing slip bands in irradiated sample A1 strained 2\%.

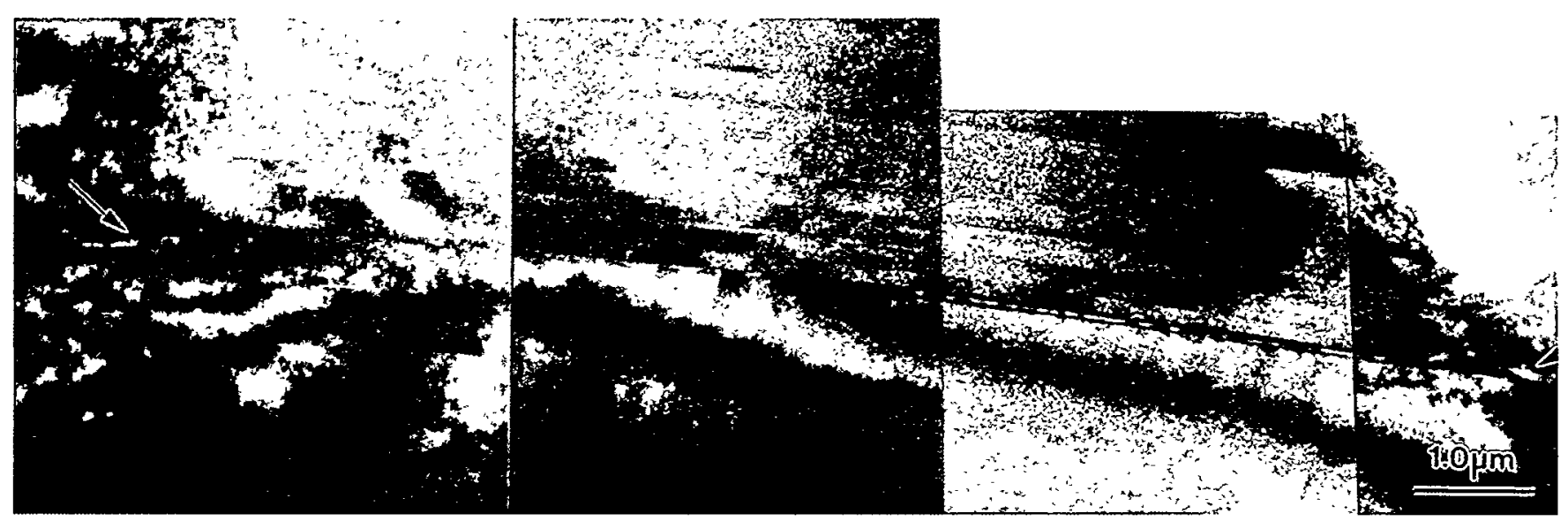

Figure 5. TEM montage of IASCC-susceptible irradiated Alloy X-750. Note intense slip band intersecting 2 grain boundaries and microcrack formation at slip band/carbide interface (arrowed).

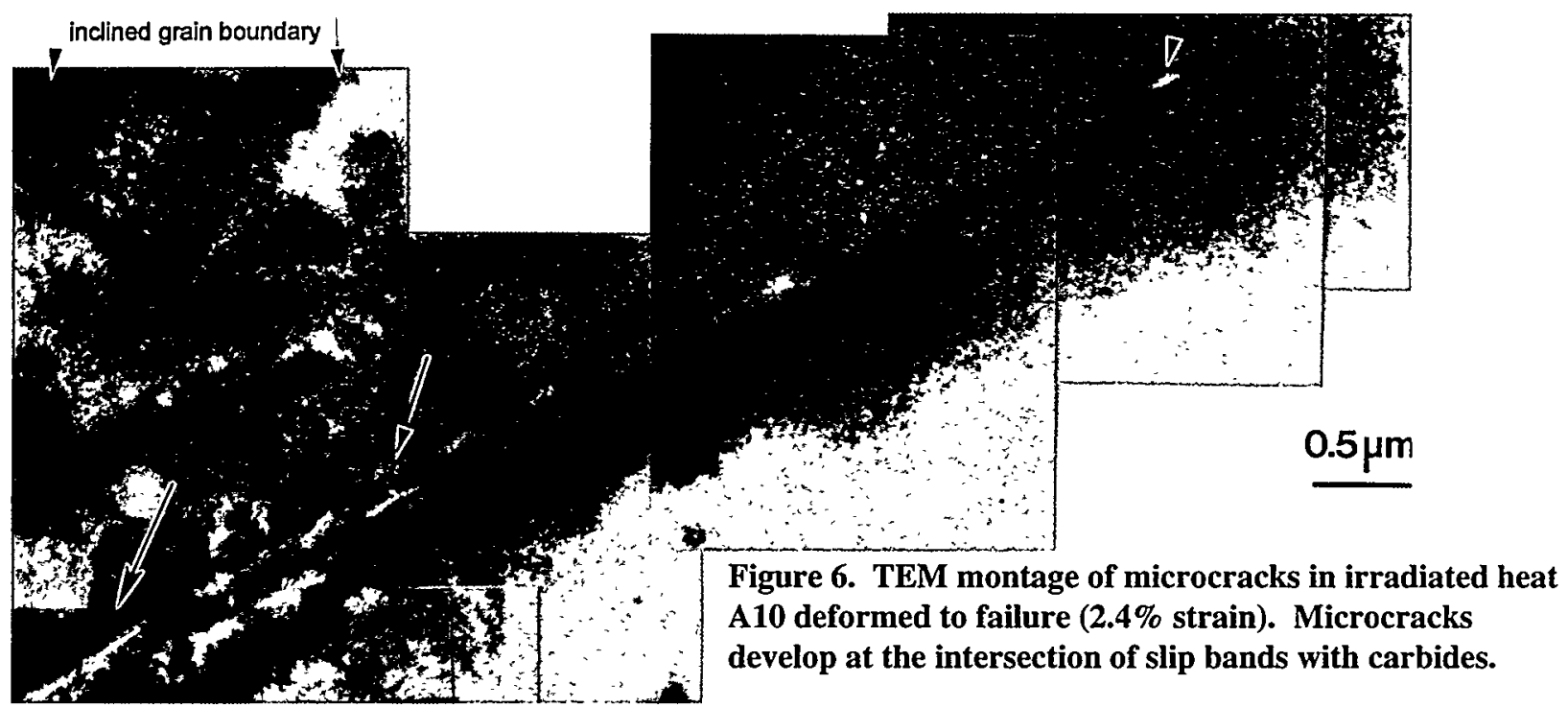




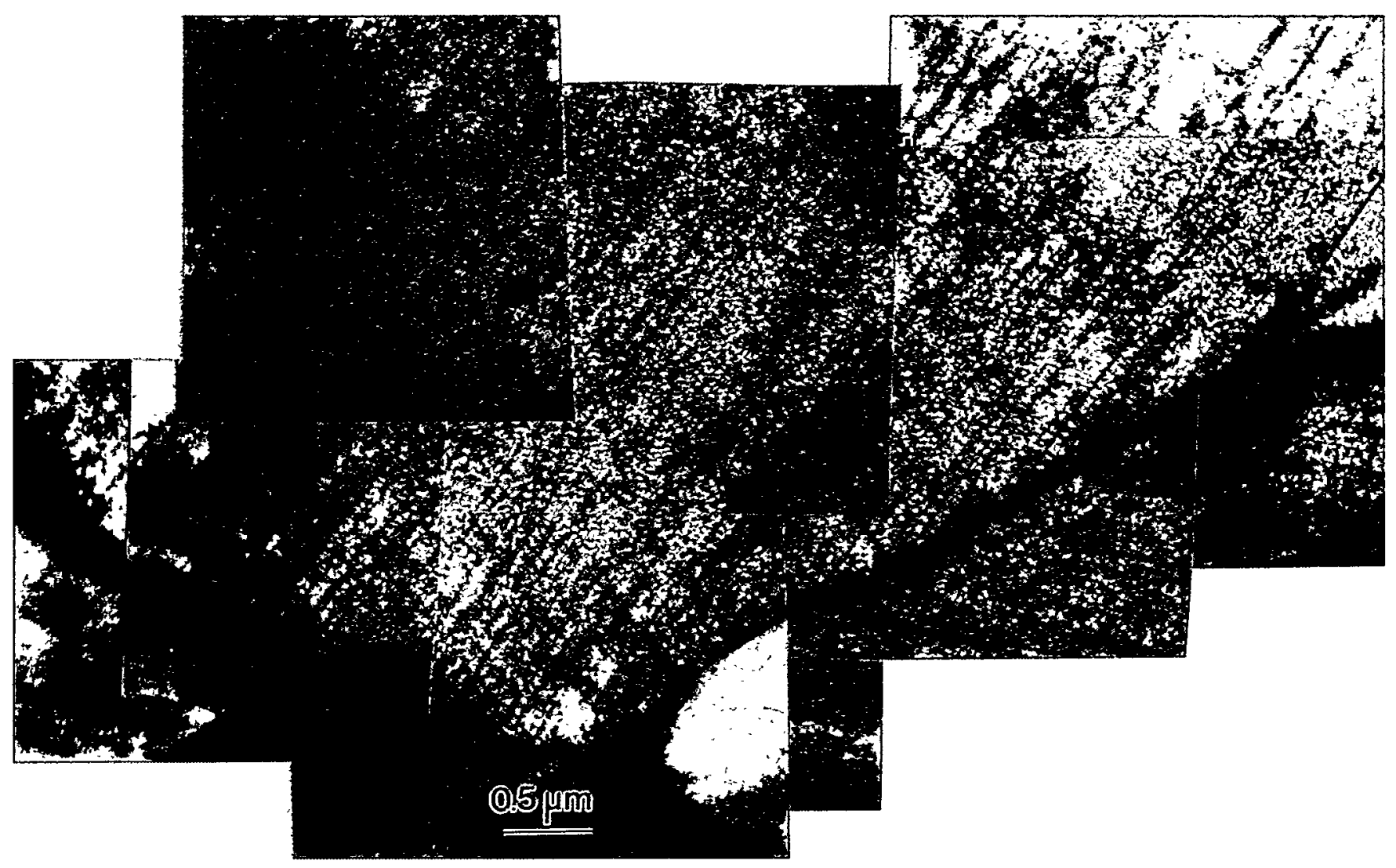

Figure 7. TEM montage of nonirradiated DA-A625 sample A12 strained 2\% showing finely spaced slip bands.

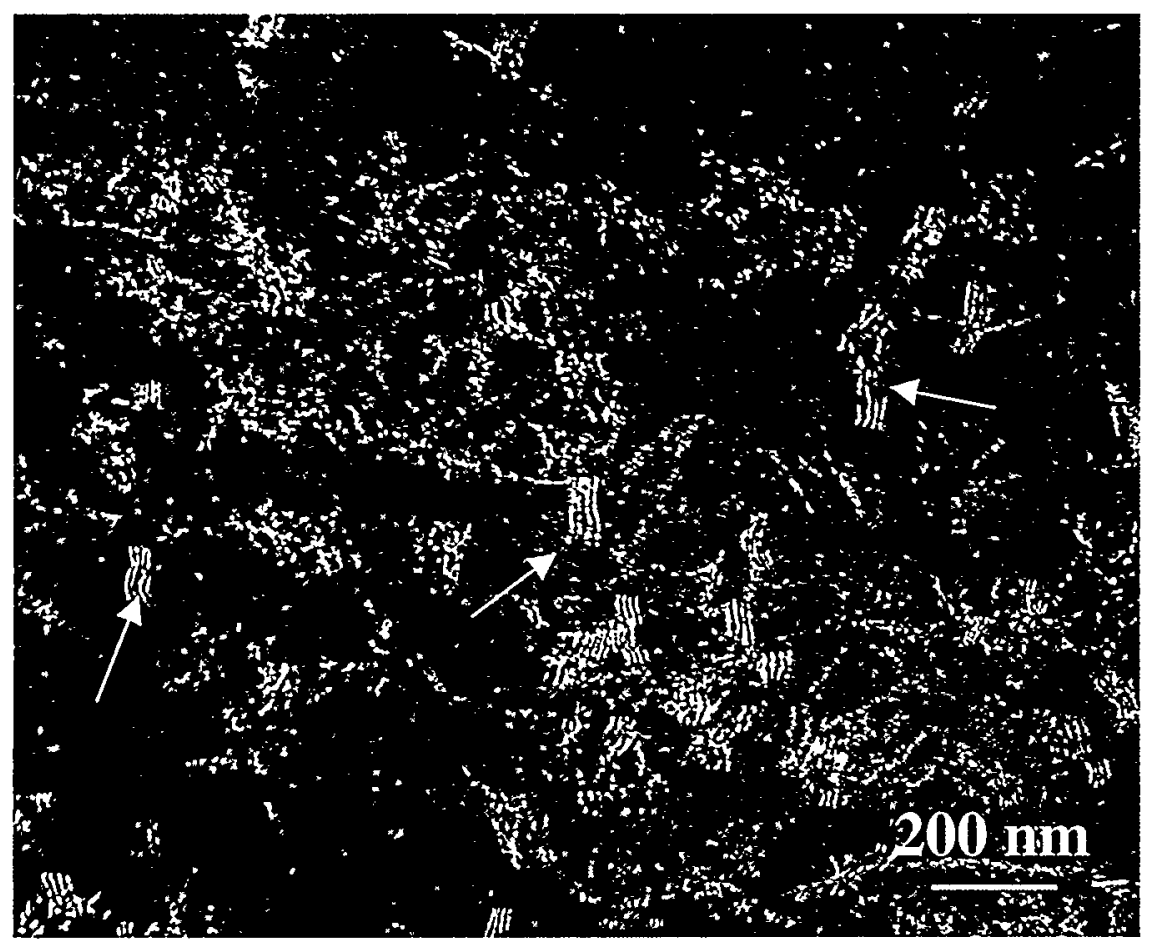

Figure 8. Dark-field TEM image of dislocations and "quartets"(arrowed) observed in deformed nonirradiated DA-A625 sample A12. 